\title{
TANGGUNGJAWAB KEPOLISIAN TIMOR LESTE TERHADAP KEKERASAN DALAM RUMAH TANGGA DI KOTA DILI
}

\author{
Oleh : \\ Hernanes Delfim Alves Silva ${ }^{1}$
}

\begin{abstract}
Household violence as an internal household issue, public issues are in handle openly through law mechanism. In response to the increasing cases of household violence, the Timor leste government then also formulate it as one of the common offenses in constitution number 7 of 2010 about household violence. This is a research by using empirical law research method, the result found two things, firstly, the special unit for the handling of victim of household violence within the scope of the national police of Timor Leste does not yet have an adequate law basis in regulating its duties and responsibilities, because the authority of the special unit is delegatively derived from the general authority owned by national police investigation agency. Second, even if there is no special law umbrella, the special unit still carries out its duties and responsibilities even if it is inadequate. The absence of special law umbrella and inadequate task and responsibilities of special unit unsupported by human resources.
\end{abstract}

Keywords: Police, Domestic Violence, Responsibility

\begin{abstract}
Abstrak
Kekerasan dalam rumah tangga sebagai persoalan internal rumah tangga semata, persoalan publik ditangani secara terbuka melalui mekanisme hukum. Menyikapi meningkatnya kasus kekerasan dalam rumah tangga, pemerintah Timor Leste juga kemudian merumuskannya sebagai salah satu delik umum dalam Undag-undang Nomor 7 Tahun 2010 tentang Kekerasan Dalam Rumah Tangga. Penelitian dengan menggunakan metode penelitian hukum empiris, hasil menemukan dua hal. Pertama, Unit Khusus Penanganan Korban Kekerasan Dalam Rumah Tangga dalam lingkup Kepolisian Nasional Timor Leste belum memiliki landasan hukum yang memadai dalam mengatur tugas dan tanggung jawabnya, karena kewenangan dimiliki unit khusus secara delegatif sebagai turunan dari kewenangan umum yang dimiliki oleh Badan Investigasi Kepolisian Nasional Timor Leste. Kedua, sekalipun tidak memiliki payung hukum khusus, namun Unit Khusus tetap melaksanakan tugas dan tanggung jawabnya sekalipun tidak memadai. ketiadaan payung hukum khusus, ketidakmemadaian pelaksanaan tugas dan tanggungjawab unit khusus tidak didukung oleh sumber daya manusia.
\end{abstract}

\section{Kata Kunci: Kepolisian, Kekerasan Rumah Tangga, Tanggungjawab}

1 Program Pascasarjana Universitas Nusa Cendana, Kupang Nusa Tenggara Timur, email: silva.hernanes@yahoo.com 


\section{PENDAHULUAN}

Keutuhan dan kerukunan rumah tangga dapat terganggu jika kualitas dan pengendalian diri tidak dapat dikontrol, yang pada akhirnya dapat terjadi kekerasan dalam rumah tangga sehingga menimbulkan ketidakamanan atau ketidakadilan terhadap orang yang berada dalam lingkup rumah tangga tersebut. Bertitik tolak dari hak asasi manusia maka Negara Timor-Leste pada Tahun 2002 untuk menjadikan hukum Nasional atau Konstitusi Republik Demokratika Timor-Leste sebagai hukum yang paling tertinggi yaitu yang tertuang dalam ketentuan Pasal 16 Tentang Universalitas masih banyak terjadi kasus kekerasan dalam rumah tangga (KDRT) yang masih dilakukan oleh laki-laki maupun perempuan.

Berdasarkan data yang di tangani oleh pihak kepolisian dalam kurun waktu 2014 sampai dengan 2016 sebanyak 984 kasus KDRT yang di perinci menjadi $935(95,02 \%)$ kasus KDRT yang dilakukan oleh lakilaki, dan sebanyak 49 (4,98\%) kasus KDRT dilakukan oleh perempuan. Data kasus KDRT di Kota Dili yang ditangani oleh Bagian Investigasi Kriminal Kepolisian Distrik Dili dari tahun 2014-2016 sebagaimana termuat dalam table berikut ini.

Tabel Statistik Kasus Kekerasan Dalam Rumah Tangga di Kota Dili Timor Leste Tahun 2014-2016

\begin{tabular}{|c|c|c|c|c|c|c|}
\hline \multirow{2}{*}{ No } & \multirow{2}{*}{ Jenis KDRT } & \multirow{2}{*}{ Pelaku KDRT } & \multicolumn{3}{|c|}{ Tahun } & \multirow{2}{*}{ Total } \\
\cline { 3 - 6 } & & & $\mathbf{2 0 1 4}$ & $\mathbf{2 0 1 5}$ & $\mathbf{2 0 1 6}$ & \\
\hline \multirow{2}{*}{1.} & \multirow{2}{*}{ Kekerasan fisik } & Laki-laki & 189 & 217 & 238 & $\mathbf{6 4 4}$ \\
\cline { 3 - 7 } & & Perempuan & 14 & 11 & 18 & $\mathbf{4 3}$ \\
\hline \multirow{2}{*}{2.} & \multirow{2}{*}{ Kekerasan Seksual } & Laki-laki & 113 & 94 & 71 & $\mathbf{2 7 8}$ \\
\cline { 3 - 7 } & & Perempuan & 5 & 0 & 1 & $\mathbf{6}$ \\
\hline \multirow{2}{*}{3.} & \multirow{2}{*}{ Kekerasan Psikologi } & Laki-laki & 2 & 2 & 8 & $\mathbf{1 2}$ \\
\cline { 3 - 7 } & & Perempuan & 0 & 0 & 0 & $\mathbf{0}$ \\
\hline \multirow{2}{*}{4.} & \multirow{2}{*}{ Kekerasan Ekonomi } & Laki-laki & 0 & 0 & 1 & $\mathbf{1}$ \\
\cline { 3 - 7 } & & Perempuan & 0 & 0 & 0 & $\mathbf{0}$ \\
\hline & \multicolumn{2}{|c|}{ T o t a I } & $\mathbf{3 2 3}$ & $\mathbf{3 2 4}$ & $\mathbf{3 3 7}$ & $\mathbf{9 8 4}$ \\
\hline
\end{tabular}

Sumber : Data statistic Biro Operasi KDRT (Violencia deomestica) tahun 2014-2016

dan Persamaan (Universalidade no Igualdade) dan pasal 17 tentang Persamaan antara Perempuan dan Laki-laki (Igualdade ba Feto no Mane). Namun realitas menunjukkan bahwa tindakan-tindakan diskriminatif masih saja terjadi di masyarakat Timor Leste. Fakta menunjukkan bahwa
Berkaitan dengan KDRT yang semakin marak terjadi di Dili Timor Leste sebagaimana diuraikan di atas, maka Polisi diharapkan tampil sebagai pilar utama dalam penanganan tindak pidana KDRT. Tampilnya Polisi dalam penanggulanganKDRT tersebutsejalan dengan amanat Pasal 147 Konstitusi 
Republik Demokratik de Timor-Leste (CRDTL) yang menempatkan institusi kepolisian dan keamanan lainnya (Polisia no forsa siguransa sira) untuk menjaga ketertiban, keamanan dan melaksanakan penegakan hukum, terutama menjadi pembantu penyidik tindak pidana. Sebagai pembantu penyidik (Kejaksaan), maka kepolisian memiliki tanggung jawab untuk menyelidiki dan memproses tindak pidana.

Kitab Undang-undang Hukum Acara Pidana (KUHAP) atau (Codigo Processo Penal) Timor Leste dalam Pasal 52 secara tegas mengatur tentang Kewenangan Umum Polisi. Ketentuan Pasal tersebut menegaskan, bahwa dalam melaksanakan tugas dan tanggung jawabnya, anggota Kepolisian Nasional Timor Leste merupakan pilar utama dalam segala permasalahan yang terjadi Timor Leste. Khusus untuk menangani tindakan kekerasan dalam rumah tangga, institusi kepolisian telah membentuk salah satu unit khusus dalam penanganan KDRT, yaitu Unidade Pessoal Vulniraveis atau disingkat VPU sebagaimana di amanatkan oleh Pasal 147 Konstitusi RDTL junto Undang-undang Nomor 9 Tahun 2009 tentang Kepolisian Nasional Timor Leste.

Bertolak dari tugas dan tanggung jawab Kepolisian tersebut, maka dalam mengidentifikasi kasus-kasus KDRT, kepolisian selalu berpedoman pada Kitab Undang-undang Hukum Pidana (Kodigo Penal), yang antara lain mengatur tentang:

(1) Pasal 153 tentang penindasan orang yang tidak berdaya (hahaat ema ne'ebe laiha kbiit),

(2) Pasal 154 tentang pelecehan terhadap suami/istri (feen-la'en dehan aat malu),

(3) Pasal 155 terhadap pelecehan terhadap anak di bawah umur (hahaat labarik ki'ik sira), dan

(4) Pasal 156 tentang dampak dari tindakan kekerasan (Agravasaun Tanba Rezultado).

Selain itu, Kepolisian Nasional Timor Leste dalam menanggulangi tindak pidana KDRT juga berpedoman pada Undang-undang Nomor 7 Tahun 2010 yang mengatur khusus tentang Kekerasan dalam Rumah Tangga (Lei Violencia Domestika). Ide dasar kehadiran Undang-undang KDRT tersebut didasarkan pada pertimbangan bahwa KDRT merupakan salah satu bentuk pelanggaran hak asasi manusia, karena merupakan kejahatan terhadap martabat kemanusiaan serta bentuk diskriminasi. Uraian di atas menunjukkan bahwa dalam upaya penanggulangan tindak pidana KDRT, di satu sisi Kepolisian Nasional sudah diberi tugas dan tanggung jawabnya dalam penanggulangan kejahatan pada umumnya, termasuk tindak pidana KDRT. Berkaitan dengan tugas dan tanggungjawab kepolisian tersebut, telah dibentuk unit penanganan tindak kekerasan dalam rumah tangga. Selain itu, secara materiil Kepolisian Nasional Timor Leste juga sudah 
dibekali dengan seperangkat peraturan perundang-undangan, Undangundang KDRT maupun KUHP serta KUHAP. Sementara di sisi yang realitas menunjukkan bahwa tindak pidana KDRT terus saja meningkat. Kondisi yang demikian itulah yang memunculkan suatu problem research yang berkaitan dengan tanggungjawab Kepolisian Nasional dalam penanggulangan tindak pidana KDRT di Timor Leste. Bertolak dari uraian latar belakang di atas maka permasalahan yang dikaji dalam penulisan ini yaitu :

1. Bagaimanakah pengaturan hukum terhadap tanggungjawab Unit penanganan korban KDRT (Invetigasi Unidade Pesoal Vulneraveis - VPU) Kepolisan Nasional Timor Leste terhadap kasus kekerasan dalam rumah tangga yang terjadi di Kota Dili?

2. Bagaimanakah implementasi Tanggungjawab Unit Penanganan Korban KDRT (Invetigasi Unidade Pesoal Vulneraveis (VPU) Kepolisan Nasional Timor Leste dalam melindungi korban KDRT?

Jurnal ini merupakan hasil karya dari penulis sendiri dan berdasarkan hasil penelusuran terhadap artikel dan jurnal ilmiah terdahulu di website tidak ditemukan jurnal atau artikel yang serupa dengan persoalan yang ditulis. Namun untuk persoalan kekerasan dalam rumah tangga bukan merupakan fenomena yang baru hal ini dibuktikan dengan adanya beberapa jurnal yang menulis tentang persoalan kekerasan dalam rumah tangga yaitu :

1. Jurnal yang di tulis oleh Tjokorda Istri Putra Astiti dari Fakultas Hukum Universitas Udayana dengan judul Sinkronisasi Dan Diferensiasi Putusan Hakim Dalam Penyelesaian KasusKasus Kekerasan Dalam Rumah Tangga, yang dimuat dalam Jurnal Magister Hukum Udayana (Udayana Master law Journal) Vol. 3, No. 2, Juli 2014. ${ }^{2}$

2. Jurnal yang ditulis oleh Anak Agung Istri Ari Atu Dewi dengan judul Dasar Kewenangan Pemerintah Daerah Kabupaten Badung Dalam Memberikan Standar Pelayanan Bagi Perempuan Dan Anak Korban Kekerasan, yang dimuat dalam jurnal Jurnal Magister Hukum Udayana (Udayana Master law Journal) Vol. 4, No. 3, September $2015 .^{3}$

2 Putra Astiti, Tjokorda Istri. SINKRONISASI DAN DIFERENSIASI PUTUSAN HAKIM DALAM PENYELESAIAN KASUSKASUS KEKERASAN DALAM RUMAH TANGGA. Jurnal Magister Hukum Udayana (Udayana Master Law Journal), vol. 3 no. 2 edisi Juli 2014. <https://ojs.unud. ac.id/index.php/jmhu/article/view/9469>. Diakses tanggal: 19 april 2017. doi: https:// doi.org/10.24843/JMHU.2014.v03.i02.p08.

3 Atu Dewi, Anak Agung Istri Ari. DASAR KEWENANGAN PEMERINTAH DAERAH KABUPATEN BADUNG DALAM MEMBERIKAN STANDAR PELAYANAN BAGI PEREMPUAN DAN ANAK KORBAN KEKERASAN.Jurnal Magister Hukum Udayana (Udayana Master Law Journal), vol. 4 no. 3 edisi September 2015. <https:// 
Tujuan dari penelitian ini adalah Untuk mengetahui dan menganalisis pengaturan hukum terhadap tanggungjawab Unit penanganan korban KDRT (Invetigasi Unidade Pesoal Vulneraveis - VPU) Kepolisan Nasional Timor Leste terhadap kasus kekerasan dalam rumah tangga yang terjadi di Kota Dili dan Untuk mengetahui dan menganalisis implementasi Tanggungjawab Unit Penanganan Korban KDRT (Invetigasi Unidade Pesoal Vulneraveis (VPU) Kepolisan Nasional Timor Leste dalam melindungi korban KDRT.

\section{METODE PENELITIAN}

Penelitian dengan fokus tema sebagaimana diuraikan pada bagian terdahulu merupakan penelitian yuridis empirik, karena penelitian ini berada di dua ranah sekaligus, yaitu ranah yuridis dan ranah empirik. Termasuk dalam ranah yuridis karena penelitian ini mau mendalami keandalan yuridis dalam mengatur tugas dan tanggung jawab Unit Penanganan Korban KDRT PNTL terhadap penanganan tindak pidana KDRT. Penelitian ini sekaligus juga berada dalam ranah empirik, karena salah satu fokus kajian yang ditelaah adalah menyangkut wujud tanggung jawab Unit Penanganan Korban KDRT dalam memberikan perlindungan terhadap korban KDRT. Penelitian dengan spesifikasi yang demikian tentunya menggunakan

ojs.unud.ac.id/index.php/jmhu/article/ view/18067>. Diakses tanggal: 19 april 2017. doi: https://doi.org/10.24843/JMHU.2015. v04.i03.p16 dua jenis data penelitian sekaligus, yaitu bahan hukum normatif berupa dokumen-dokumen hukum) maupun data empirik yang diperoleh di lapangan (lokasi penelitian) ${ }^{4}$.

III. HASIL DAN PEMBAHASAN

3.1 Pengaturan hukum terhadap tanggungjawab Unit penanganan korban KDRT (Invetigasi Unidade Pesoal Vulneraveis - VPU) Kepolisian Nasional Timor Leste terhadap kasus kekerasan dalam rumah tangga yang terjadi di Kota Dili

Berbicara tentang tugas dan fungsi kepolisian, termasuk Unit Penanganan Korban KDRT Kepolisian Nasional Timor Leste, sesungguhnya pembicaraan itu mengarah ke masalah kekuasaan. Jika ditelusuri lebih jauh, masalah kekuasaan itu sendiri sudah menjadi bahan perdebatan para filsuf Yunani kuno sejak ribuan tahun yang lalu dalam kaitannya dengan moral sebagai bagian dari studi tentang filsafat etika. Menurut Muladi kekerasan terhadap perempuan saat ini tidak hanya merupakan masalah individual atau masalah nasional, tetapi sudah merupakan masalah global. Dalam halhal tertentu bahkan dapat dikatakan sebagaimasalahtransnasional ${ }^{5}$. Bahkan

4 Bahder Johan Nasution, Metode Penelitian Hukum, , Bandung, CV. Mandar Maju, hlm 162.

5 Dwi Hapsari Retnaningrum, INCEST SEBAGAI BENTUK MANIFESTASI KEKERASAN TERHARAP PEREMPUAN, Jurnal Dinamika Hukum, Vol. 9 No. 1 Edisi Januari 2009, hlm. 23. 
dalam pembangunan perempuan selalu menjadi korban ataupun perempuan selalu diberlakukan secara tidak adil atau adanya diskriminasi terhadap perempuan seperti yang dinyatakan oleh Khusnul Khotimah ${ }^{6}$ dalam jurnal nya bahwa Dalam pembangunan pemberdayaan perempuan yang terjadi selama ini permasalahan mendasar yang masih dialami adalah rendahnya partisipasi perempuan dalam pembangunan, di samping masih adanya berbagai bentuk praktik diskriminasi terhadap perempuan. Rendahnya kualitas hidup perempuan terjadi di berbagai lini, antara lain sosial budaya, lingkungan, pendidikan, kesehatan, ekonomi, dan politik.

Kekerasan terhadap perempuan sudah ada dan terjadi sejak dahulu kala, kekerasan terhadap perempuan bisa terjadi karena budaya yang lebih mengutamakan kaum pria sebagai orang yang berkuasa atau dengan kata lain dengan kekuasaan yang ada pada kaum pria maka seenaknya menindas kaum wanita sehingga, wanita selalu tidak dianggap martabatnya sebagai seorang yang punya hak untuk bebas dari penindasan dan diskiriminasi seperti yang dinyatakan oleh Puji Astuti $^{7}$ bahwa Sejarah kekerasan terhadap istri dimulai dari sejarah umat

6 Khusnul Khotimah, DISKRIMINASI GENDER TERHADAP PEREMPUAN DALAM SEKTOR PEKERJAAN, Jurnal Studi Gender Dan Anak, Vol. No 1 JanuariJuni 2009. PP 158-180, , hlm 1

7 Puji Astuti, KEMANDIRIAN DAN KEKERASAN TERHADAP ISTRI, Jurnal Buletin Psikologi, Tahun X No. 2, Desember 2002, hlm 2 manusia itu sendiri. Pada awalnya lakilaki dan perempuan memiliki peran dan kedudukan yang relatif sama dalam menjalankan kehidupan seharihari. Mereka berdua adalah pemburu, sampai fungsi perempuan berkurang karena ia berada di rumah untuk mengurusipekerjaan rumah.Perbedaan peran yang bermula dari perbedaan fisiologis ini memunculkan konsep keunggulan laki-laki karena secara fisik ialah penyelamat keluarga.

Hingga saat ini semua lapisan masyarakat, mulai dari para pemikir, pakar, akademisi, para penguasa sendiri, dan masyarakat umum pada lapisan yang paling bawah pun tidak ketinggalan berbicara tentang makna dari kekuasaan. Salah satu disiplin ilmu yang mendedikasikan lebih banyak waktu, tenaga dan pikiran demi pemahaman tentang kekuasaan adalah ilmu psikologi sosial. Oleh karena itu melalui organisasi serta proses-proses di dalamnya, masyarakat menerima perwujudan dari tujuan hukum. Secara sosiologis untuk mengkaji perlindungan hukum terhadap korban kekerasan dalam rumah tangga ${ }^{8}$ perlu dilihat hukum dalam kaitannya dengan satu sistem. Dalam hal ini Lawrence M Friedman berpendapat, bahwa " $A$ legal systeme in actual operation is complex organism in wich structutre,

8 Siti Muflicchah dan Rahadi Wasi Bintoro, TRAFFICKING: SUATU STUDI TENTANG PERDAGANGAN PEREMPUAN DARI ASPEK SOSIAL, BUDAYA DAN EKONOMI DI KABUPATEN BANYUMAS, Jurnal Dinamika Hukum, Vol. 9 No. 1 Januari 2009, hlm. 127. 
substance, and culture interact" oleh karena itu, menurut Lawrence M Friedman, dalam pelaksanaannya hukum berfungsi sebagai pengawasan atau pengendalian sosial (social control) dan penyelesaian sengketa (dispute settlement).

Sehubungan dengan pelaksanaan tugas guna mengejawantahkan fungsi, tujuan, dan perannya sebagaimana diuraikan di atas, kekuasaan kepolisian terkadang dapat menampilkan banyak "wajah" dan "karakter" yang dapat berubah-ubah sesuai konteks atau sesuai dengan situasi dan kondisi di mana polisi itu berada. Minimal kekuasaan kepolisian itu dapat tampil dalam dua bentuk: ${ }^{9}$

1) Terkadang kekuasaan polisi dipakai untuk mempertahankan status quo (kemapanan pada suatu waktu dan tempat tertentu);

2) Disaatyang lain kekuasaan polisi justru dimanfaatkan sebagai 'wahana' atau 'kendaraan' bagi berlangsungnya perubahan politik, sosial, ekonomi, budaya, dan lain sebagainya.

Semua negara di dunia, termasuk Timor Leste, memiliki tekad yang sama untuk membangun institusi kepolisian yang kuat. Hal ini sejalan dengan teori kepolisian yang dikemukakan oleh Reckles sebagaimana dikutip oleh Anton Tabah bahwa: "disiplin bangsa hanya bisa tumbuh apabila memiliki Angkatan Kepolisian (Police Force) yang kuat dan tangguh dengan sistem organisasi kepolisian yang baik."

9 Erlyn Indarti, Op. Cit., hlm. 33.
Teori kepolisian tersebut memperkuat pendirian bahwa kepolisian yang kuat menjadi prasyarat penting dalam bermasyarakat, berbangsa dan bernegara. Di tangan kepolisian yang kuat sajalah yang akan menjadikan undang-undang menjadi hukum yang hidup, dan sebaliknya di tangan kepolisian yang lemah akan membuat undang-undang bagaikan barang mati ${ }^{10}$. Namun dalam menjalankan tugas kepolisian juga harus berpegang teguh terhadap hukum dan etika profesi sehingga ketika polisi menjadikan hukum yang hidup polisi juga menjadi panutan bagi masyarakat seperti yang dikatakan oleh Agus Raharjo dan Angkasa ${ }^{11}$ bahwa Polisi dalam menjalankan tugasnya sebagai penegak hukum, bukan hanya harus tunduk pada hukum yang berlaku sebagai aspek luar, mereka dibekali oleh etika kepolisian sebagai aspek dalam kepolisian.

Bertolak dari uraian pengantar di atas, berikut ini akan digambarkan tentang otoritas yang dimiliki oleh Kepolisian Nasional Timor Leste pada umumnya, dan pada khususnya mengenai Unit yang dibentuk untuk secara khusus menangani Korban KDRT. Ada dua hal yang berkaitan dengan otoritas kepolisian yang akan dianalisis dalam uraian selanjutnya, yakni berkaitan dengan masalah

10 Anton Tabah, 2002, Membangun Polri yang Kuat: Belajar dari Macan-macan Asia. Jakarta, PT Sumbersewu Lestari, hlm. 3.

11 Agus Raharjo dan Angkasa, PROFESIONALISME POLISI DALAM PENGAKAN HUKUM, Jurnal Dinamika Hukum, Vol. 11 No. 3 September 2011, hlm 2 
kedudukan Unit Penanganan Korban KDRT dalam Sistem Kepolisian nasional Timor Leste; dan mengenai pengaturan tentang mekanisme penanganan tindak pidana KDRT.

Sebelum kedua hal yang berkaitan langsung Unit Penanganan Korban KDRT dalam Sistem Kepolisian nasional Timor Leste, alangkah baiknya diawali dengan memperkenalkan lebih detail tentang tugas dan fungsi Kepolisian Nasional Timor Leste secara umum. Pembahasan yang dimulai dari hal yang umum ke hal-hal yang lebih spesifik ini dimaksudkan agar dapat diperoleh pemahaman yang lebih komprehensif tentang permasalahan yang dibahas dalam tesis ini. Pola pembahasan yang demikian juga dimaksudkan agar dapat diketahui posisi Unit Penanganan Korban KDRT dalam mendukung tugas dan fungsi tertentu dari Kepolisian nasional Timor Leste.
3.2 Tanggungjawab

Unit

Penanganan Korban KDRT (Invetigasi Unidade Pesoal Vulneraveis (VPU) Kepolisian Nasional Timor Leste dalam melindungi korban KDRT

Kebijakan perlindungan korban kejahatan pada hakikatnya merupakan bagian dari kebijakan kriminal (criminal policy), dan kebijakan kriminal tersebut sesungguhnya merupakan bagian kebijakan perlindungan masyarakat (social defence policy). Jika dilihat secara lebih luas, maka dapatlah dipahami bahwa kebijakan perlindungan masyarakat itu sendiri merupakan bagian integral dari kebijakan sosial (social policy). Pada dasarnya baik kebijakan kriminal secara khusus maupun kebijakan sosial pada umumnya berorientasi pada upaya untuk mencapai kesejahteraan sosial (social welfare). ${ }^{12} \quad$ Secara skematis hubungan antara kebijakan sosial dengan kebijakan kriminal dapat dilihat dalam bagan berikut ini.

Bagan Orientasi Kebijakan Kriminal sebagai Bagian dari Kebijakan Sosial ${ }^{13}$

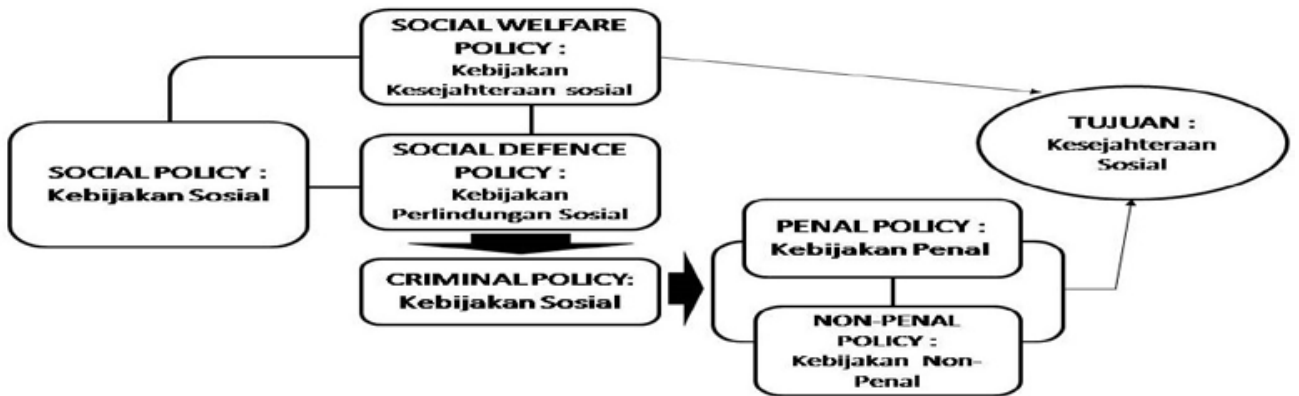

Sumber : Barda Nawawi Arief, 1991, Upaya Non Penal Dalam Penanggulangan Kejahatan, Semarang PT. Citra Aditya Bakti

12 Barda Nawawi Arief, 2016, Kebijakan Kriminal (Criminal Policy). Semarang , UNDIP , hlm. 2-3.

13 Barda Nawawi Arief, 1991, Upaya Non Penal Dalam Penanggulangan Kejahatan, Semarang PT. Citra Aditya Bakti, hlm. 3 
Mengikuti jalan pikiran yang demikian, maka dapat kita katakan bahwa dalam konteks tujuan, antara kebijakan dan kebijakan sosial mempunyai persamaan atau mempunyai korelasi yang sangat erat. Sama halnya dengan kebijakan sosial pada umumnya, kebijakan kriminal juga berusaha dengan caranya sendiri membangun kesejahteraanmasyarakat. Melalui sarana penal maupun nonpenal, kebijakan kriminal berusaha menyiapkan kondisi sosial yang aman dan tertib sehingga memungkinkan terwujudnya kesejahteraan masyarakat.

Perlindungan kepada korban sekaligus mengandung pengertian memberikan pula "perlindungan kepada masyarakat", karena eksistensi individu itu sendiri sebagai bagian dari kehidupan masyarakat. Dengan kata lain, masyarakat itu terdiri dari individu-individu, oleh karena antara masyarakat dan individu saling berhubungan dan saling melengkapi. Sebagai konsekuensinya adalah bahwa antara individu dan masyarakat saling mempunyai hak dan kewajiban. Walaupun disadari bahwa antara masyarakat dan individu memiliki kepentingan yang berbeda, akan tetapi harus terdapat keseimbangan pengaturan dan antara hak dan kewajiban di antara keduanya itu sebab hukum itu ada untuk manusia sehingga hukum harus memberikan rasa adil seperti yang dinyatakan oleh Satjipto Raharjo dalam jurnalnya Hamidah
Abdurrachman ${ }^{14}$ bahwa hukum adalah karya manusia yang berupa karya manusia yang berisi petunjuk tingkah laku, merupakan pencerminan dan kehendak manusia tentang bagaimana seharusnya masyarakat dibina dan dibawa ke arah mana. Oleh karena itu hukum mengandung rekaman ide-ide yang dipilih masyarakat dari tempat hukum diciptakan, yaitu ide keadilan.

Mengingat

kebijakan perlindungan korban merupakan bagian integral dari kebijakan kriminal dan kebijakan sosial menuju perwujudan kesejahteraan sosial, maka diperlukan seperangkat kegiatan yang memungkinkan korban kejahatan mendapatkan perlindungan memadai, meliputi: ${ }^{15}$

1. Pelayanan kesehatan: Dilakukan oleh tenaga kesehatan di sarana kesehatan milik pemerintah, pemerintah daerah (distrik), dan masyarakat, termasuk swasta dengan cara memberikan pelayanan pengobatan dan pemulihan kesehatan korban. Dalam memberikan pelayanan kesehatan kepada korban, tenaga kesehatan melakukan beberapa upaya sebagai berikut:

14 Hamidah Abdurrachman, PERLINDUNGAN HUKUM TERHADAP KORBAN KEKERASAN DALAM RUMAH TANGGA DALAM PUTUSAN PENGADILAN NEGERI SEBAGAI IMPLEMENTASI HAKHAK KORBAN, Jurnal Hukum NO. 3 VOL. 17 JULI 2010: 475 - 491, hlm 8.

15 Badriyah Khaleed, 2015, Penyelesaian Hukum Kdrt: Penghapusan Kekerasan Dalam Rumah Tangga Dan Upaya Pemulihannya. Yogyakarta: Pustaka Yustitia, hlm. 38. 
a) Anamnesis kepada korban;

b) Pemeriksaan kepada korban;

c) Pengobatan penyakit;

d) Pemulihan kesehatan, baik fisik maupun psikis;

e) Konseling

f) Merujukkesaranakesehatan yang lebih memadai bila diperlukan;

g) Dalam kasus-kasus tertentu tenaga kesehatan dapat melakukan pelayanan keluarga berencana darurat untuk korban perkosaan, dan pelayanan kesehatan reproduksi lainnya sesuai dengan kebutuhan medis.

2. Pendampingan korban:

Dilakukan oleh tenaga kesehatan, kerja sosial, relawan pendamping, atau pembimbing rohani dengan cara memberikan konseling, terapi, bimbingan rohani dan advokasi guna penguatan dan pemulihan diri korban;

3. Konseling: Dalam hal ini berkaitan dengan pemberian bantuan oleh seseorang yang ahli atauorangyangterlatihsedemikan rupa sehingga pemahaman dan kemampuan psikologis diri korban meningkat dalam memecahkan permasalahan yang dihadapi. Pemberian konseling dilakukan oleh pekerja sosial, relawan pendamping, dengan mendengarkan secara empati dan menggali permasalahan untuk penguatan psikologis korban;

4. Bimbingan rohani konseling: Dilakukan oleh pembimbing rohani dengan cara memberikan penjelasan mengenai hak dan kewajibannya, serta penguatan iman dan takwa sesuai dengan agama dan kepercayaan yang dianut nya;

5. Resosialisasi: Dilaksanakan oleh instansi sosial dan lembaga sosial agar korban dapat kembali melaksanakan fungsi sosialnya dalam masyarakat. Instansi Sosial adalah instansi pemerintah yang ruang lingkup tugasnya menangani urusan sosial, dan instansi pemerintahan daerah (distrik) yang menanggulangi masalah sosial.

Untuk penyidikan, tenaga kesehatan yang berwenang harus membuat Vicum et Repertum dan visum et Repertum Psichiatricum atau membuat surat keterangan medis. visum et Repertum dibuat oleh dokter yang memeriksa korban, sedangkan Vicum et Repertum Psichiatricum dibuat oleh dokter spesialis kesehatan jiwa. Sementara pekerja sosial dalam memberikan pelayanan kepada korban dapat dilakukan di rumah aman, pusat pelayanan atau tempat tinggal alternatif milik pemerintah, pemerintah daerah (Distrik) atau masyarakat. Dalam hal diperlukan dan atas persetujuan korban, pelayan sosial dapat menempatkan korban 
di rumah aman, pusat pelayanan, atau tempat tinggal alternatif yang aman untuk melindungi korban dari ancaman. Pengadaan rumah aman, pusat pelayanan, atau tempat tinggal alternatif yang dilakukan masyarakat dapat difasilitasi oleh pemerintah dan atau pemerintah daerah sesuai dengan ketentuan peraturan perundangundangan $^{16}$

Selanjutnya dalam memberikan pelayanan pemulihan kepada korban, pekerja sosial dapat melakukan sejumlah upaya sebagai berikut: ${ }^{17}$

a) Menggali permasalahan korban untuk membantu pemecahan masalahnya;

b) Memulihkan korban dari konsekuensi traumatis melalui terapi psiko-sosial;

c) Melakukan rujukan ke rumah sakit atau rumah amat atau pusat pelayanan atau tempat alternatif lainnya sesuai dengan kebutuhan korban;

d) Mendampingi korban dalam upaya pemulihan melalui pendampingan dan konseling;

e) Melakukan resosialisasi agar korban dapat kembali melaksanakan fungsi sosialnya di dalam masyarakat.

Sebagaimana diuraikan pada bagian terdahulu bahwa dalam sistem pelayanan korban KDRT di Timor Leste, pihak PNTL telah membentuk Unit Pelayan Korban KDRT (VPU)

16 Badriyah Khaleed. Ibid., hlm. 38-41.

17 Badriyah Khaleed. Ibid., hlm. 41. yang secara khusus bertugas untuk menangani korban baik secara yudisial maupun non-yudisial. Penanganan korban secara yudisial dapat berupa tindakan-tindakan yang berkaitan dengan perlindungan korban dalam proses penanganan kasus KDRT secara hukum. Sedangkan, penanganan korban secara non-yudisial adalah upaya-upaya yang berkaitan dengan pemulihan korban baik secara medis maupun psiko-sosial dan sebagainya. Berkaitan dengan penanganan korban KDRT secara non-yudisial, pihak VPU PNTL biasanya bekerja sama dengan LSM yang bergerak dalam bidang penanganan korban KDRT.

Berikut ini akan dipaparkan secara empirik wujud tanggung jawab Unit Penanganan Korban KDRT Kepolisian Nasional dalam memberikan perlindungan terhadap korban yakni: (1) mengenai upayaupaya yang dilakukan oleh Unit Penanganan Korban KDRT dalam memberikan perlindungan terhadap korban; dan (2) mengenai respon dari Unit Penanganan Korban KDRT terhadap kasus tindak pidana KDRT yang dilaporkan atau diadukan kepadanya.

IV. KESIMPULAN

1. Tanggungjawab Unit Penanganan Korban KDRT (Investigasi Unidade Pesoal Vulneraveis - VPU) belum diatur secara memadai dalam sistem hukum Kepolisian 
Nasional Timor Leste maupun dalam Undang-undang tentang Anti KDRT dan dalam KUHAP Timor Leste. Ketidakmemadaian pengaturan hukum yang demikian itu menyebabkan VPU tidak bekerja secara maksimal dalam penanganan korban KDRT di Timor Leste.

2. Tugas dan tanggungjawab VPU dalam penanganan korban KDRT diwujudkan dalam sejumlah program kegiatan, antara lain berupaya secara proaktif mencegah terjadinya KDRT, membuat laporan investigasi mengenai kasus KDRT, mengidentifikasi kasus KDRT untuk mendapatkan bukti-bukti yang dikehendaki.

\section{DAFTAR PUSTAKA}

\section{Buku-Buku}

Anton Tabah, 2002, Membangun Polri yang Kuat: Belajar dari Macan-macan Asia. Penerbit PT Sumbersewu Lestari, Jakarta

Badriyah Khaleed.2015, Penyelesaian Hukum KDRT: Penghapusan Kekerasan dalam Rumah Tangga dan Upaya Pemulihannya. Pustaka Yustitia, Yogyakarta

Bahder Johan Nasution, Metode Penelitian Hukum, CV. Mandar Maju, Bandung.

Barda Nawawi Arief, 1991, Upaya Non Penal Dalam Penanggulangan Kejahatan, PT. Citra Aditya Bakti, Semarang
Barda Nawawi Arief, 2016, Kebijakan Kriminal (Criminal Policy). UNDIP, Semarang.

\section{Jurnal Ilmiah}

Agus Raharjo dan Angkasa, Profesionalisme Polisi Dalam Pengakan Hukum, Jurnal Dinamika Hukum, Vol. 11 No. 3 September 2011.

Atu Dewi, Anak Agung Istri Ari. DASAR KEWENANGAN PEMERINTAH DAERAH KABUPATEN BADUNG DALAM MEMBERIKAN STANDAR PELAYANAN BAGI PEREMPUAN DAN ANAK KORBAN KEKERASAN.JurnalMagister Hukum Udayana (Udayana Master Law Journal), vol. 4 no. 3 edisi September 2015. $<$ https://ojs.unud.id/index. php/jmhu/article/view/18067>. Diakses tanggal: 19 april 2017. doi: https://doi.org/10.24843/ JMHU.2015.v04.i03.p16.

Dwi Hapsari Retnaningrum, Incest Sebagai Bentuk Manifestasi KekerasanTerharapPerempuan, Jurnal Dinamika Hukum, Vol. 9 No. 1 Edisi Januari 2009

Hamidah

Abdurrachman, Perlindungan Hukum Terhadap Korban Kekerasan Dalam Rumah Tangga dalam Putusan Pengadilan Negeri Sebagai Implementasi Hak-Hak Korban, Jurnal Hukum NO. 3 VOL. 17 JULI 2010: 475 - 491 
Khusnul Khotimah, Diskriminasi

Gender Terhadap Perempuan

Dalam Sektor Pekerjaan, Jurnal

Studi Gender Dan Anak, Vol.

No 1 Januari-Juni 2009. PP 158-

180

Puji Astuti, Kemandirian Dan

Kekerasan Terhadap Istri, Jurnal

Buletin Psikologi, Tahun X No.

2, Desember 2002

Putra Astiti, Tjokorda Istri. SINKRONISASI DAN

DIFERENSIASI PUTUSAN

HAKIM DALAM

PENYELESAIAN KASUS-

KASUSKEKERASANDALAM

RUMAH TANGGA. Jurnal

Magister Hukum Udayana

(Udayana Master Law

Journal), vol. 3 no. 2 edisi

Juli 2014. <https://ojs.unud.

ac.id/index.php/jmhu/article/ view/9469>. Diakses tanggal:

19 april 2017. doi: https://doi. org/10.24823/JMHU.2014.v03. i02.p08.

Siti Muflicchah dan Rahadi Wasi Bintoro, Trafficking: Suatu Studi Tentang Perdagangan Perempuan Dari Aspek Sosial, Budaya dan Ekonomi di Kabupaten Banyumas, Jurnal Dinamika Hukum, Vol. 9 No. 1 Januari 2009. 